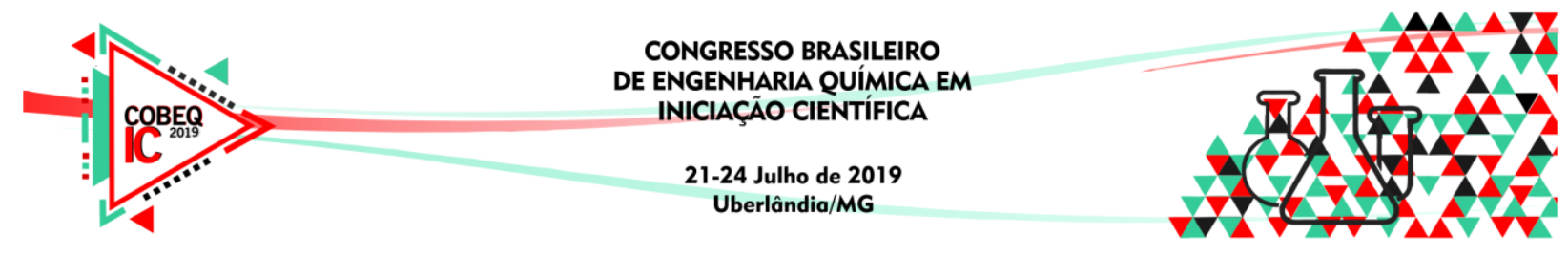

\title{
ESTUDO COM TROCADORES DE ÍONS PARA A DETERMINAÇÃO DE FERRO DISPONÍVEL PARA PLANTAS EM SOLOS DA REGIÃO DE FORMIGA-MG.
}

\author{
L. C. C. GOMES ${ }^{1}$, A. M. ALMEIDA' ${ }^{2}$, A. C. R. FONSECA ${ }^{2}$ e A. M. MUCHON ${ }^{1}$ \\ ${ }^{1}$ Centro Universitário de Formiga, Curso de Engenharia Química \\ ${ }^{2}$ Centro Universitário de Formiga, Pesquisador do UNIFOR-MG \\ E-mail para contato: luanacamargos_gomes@hotmail.com
}

\begin{abstract}
RESUMO - O solo é fundamental em qualquer ecossistema no planeta, sendo de extrema importância para o crescimento das plantas. Para a realização do cultivo, de forma adequada, é imprescindível conhecer a composição química do solo e suas condições, em especial o teor de nutrientes disponíveis para favorecer certos cultivares. Desta forma, o presente trabalho teve como objetivo verificar a quantidade disponível de ferro no solo, que pode ser absorvida pela planta, considerando a umidade e o tipo de solo, elaborando um procedimento de extração de nutrientes disponíveis para plantas utilizando resina de troca iônica. A principal dificuldade da análise reside na determinação precisa da quantidade de cada elemento que o solo possui, e que se encontra disponibilizada para as plantas. Para se obter o teor do elemento retirado do solo pela resina, foi utilizado uma solução extratora, desenvolvida pelo uso de uma mistura entre ácido clorídrico e oxalato de amônia, otimizada através de um planejamento estatístico, a qual foi aplicada na avaliação do elemento.
\end{abstract}

\section{INTRODUÇÃO}

A análise química do solo para fins de avaliação da fertilidade é a mais importante forma de análise química aplicada na agricultura. Essas análises são feitas para consentir e orientar o agricultor quanto às suas precisões na aplicação de nutrientes em adubação de plantas cultivadas. Como a avaliação dos teores disponíveis de nutrientes é complexo, devido à existência de várias formas químicas encontradas em cada solo para um mesmo elemento, é feita uma escolha de um método de extração, para cada elemento. Deve-se levar em consideração a correlação entre os teores do nutriente no solo, obtidos pelo extrator em questão, e as quantidades dos nutrientes absorvidos dos solos pela planta (Almeida, 1999).

A aquisição de um extrator multielementar é uma procura constante de aperfeiçoamento, destinando-se para a otimização do processo de análises mais rápidas, adequadas, versáteis e compensáveis para o agricultor (Scharlau, 2012).

O atual estudo teve como objetivo verificar no solo, a ocorrência do elemento ferro, e sua disponibilidade em função da umidade, por ser um dos micronutrientes catiônicos mais abundante nos solos brasileiros. 


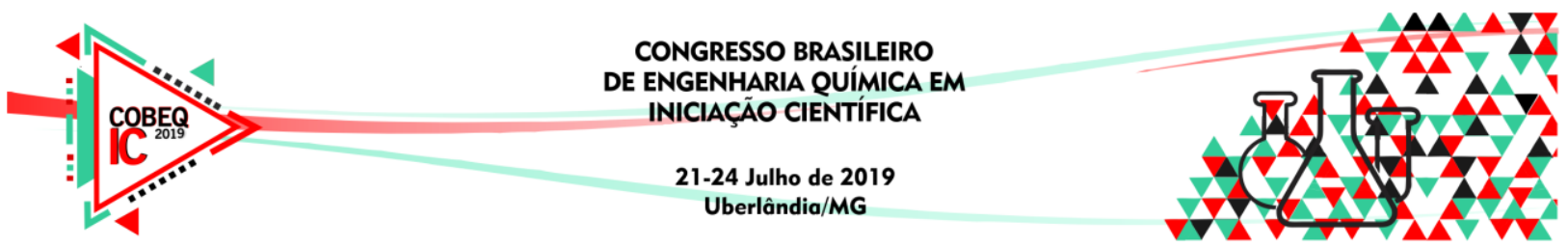

Para obter o teor do elemento retirado do solo, o presente trabalho utilizou uma mistura de resina catiônica e aniônica na proporção 1:1. Existe uma grande quantidade de trabalhos relatando o uso de resinas na determinação dos elementos considerados disponíveis e presentes no solo, e estes estudos exibem uma boa correlação solo/planta (Teodoro, 2014).

A troca iônica consiste na troca de íons de mesma carga entre a resina e a solução. A resina trocadora de íons utiliza seus próprios íons contidos nela para que a troca se processe com eficiência e rapidez. O sólido deve ter uma composição molecular permeável e aberta, para que os íons e as moléculas da solução tenham a capacidade de mover-se livremente dentro da estrutura (Vogel, 2002).

\section{METODOLOGIA}

O trabalho utilizou-se de uma mistura contendo resina catiônica (Amberlite IR120 de 50 mesh) e aniônica (Amberlite IRA402 de 50 mesh) na proporção 1:1. Para a utilização da resina com eficácia, foram necessários alguns cuidados. O procedimento para tratamento e recuperação da resina foi efetuado para eliminar os íons retidos na resina após o processo de pré-condicionamento ou por ter sido empregada em extrações de acordo com Almeida (1999).

Com base na sugestão de Helfferich (1962), uma mistura de resina de troca iônica na mesma proporção de $1: 1(\mathrm{~m} / \mathrm{m})$ foram pesadas em uma balança analítica, sendo $50 \mathrm{~g}$ de resina catiônica e $50 \mathrm{~g}$ de aniônica, colocadas em um mesmo recipiente, misturadas e homogenizadas. Essa mistura foi lavada 5 vezes com volumes de soluções apropriados a massa de resina, sendo empregados $500 \mathrm{~mL}$ de água deionizada e, em seguida $500 \mathrm{~mL}$ de $\mathrm{HCl}$ $1,0 \mathrm{~mol} / \mathrm{L}$. Posteriormente, a resina foi novamente lavada com $1 \mathrm{~L}$ de $\mathrm{NH}_{4} \mathrm{Cl} \mathrm{1,0} \mathrm{mol} / \mathrm{L}$. Completando, utilizou-se $500 \mathrm{~mL}$ de água deionizada. Assim, a resina permaneceu em contato com água deionizada até o seu uso.

Pequenas porções deste material foram acondicionadas em flanelas brancas, com a forma de pequenos "pacotes", contendo $10 \mathrm{~g}$ de resina em cada pacote. Em seguida, colocados em contato com o solo contido em vasos durante 8 dias, para a concretização das medidas de disponibilidade dos nutrientes. Os solos utilizados foram da Fazenda Laboratório do Centro Universitário de Formiga e o localizado no Museu da cidade de Pains, colocados em vasos, contendo $280,320,360$ e $400 \mathrm{~g}$ de cada solo e posteriormente as massas de solo foram igualadas com água deionizada, até atingir o total de $400 \mathrm{~g}$, visando verificar a influência da umidade.

Para realizar a retirada dos íons retidos na resina após 8 dias de contato, primeiramente foi preparada uma solução extratora (Equação 1), constituída por ácido clorídrico e oxalato de amônia:

$\mathrm{HCl} 0,5 \mathrm{~mol} / \mathrm{L}+\left(\mathrm{NH}_{4}\right)_{2} \mathrm{C}_{2} \mathrm{O}_{4} 0,25 \mathrm{~mol} / \mathrm{L}$

Conforme Vogel (2002) para a determinação do ferro dispôs-se da solução de ortofenantrolina. Utilizou-se de uma solução contendo $9,096 \times 10^{-2} \mathrm{~mol} / \mathrm{L}$ de 1,10 -fenantrolina, solubilizada em $100 \mathrm{~mL}$ de $\mathrm{C}_{3} \mathrm{H}_{6} \mathrm{O}$ (Cetona). 

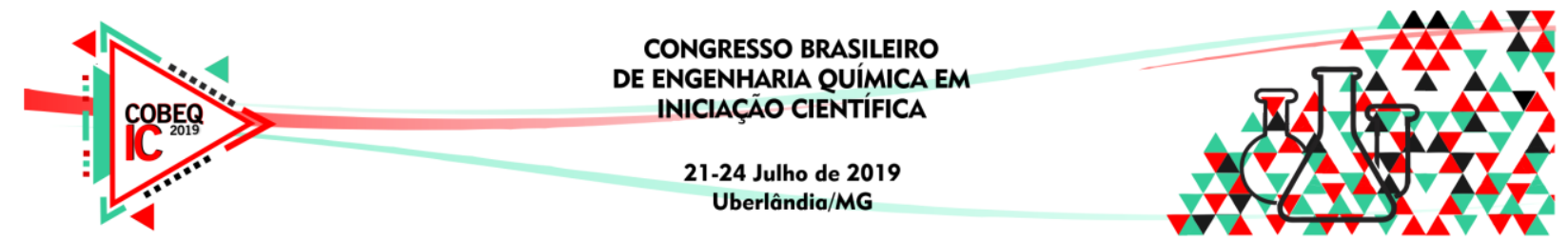

Para verificar o teor do elemento ferro extraído pela resina, o conteúdo dos pacotes foi colocado em frascos contendo $50 \mathrm{~mL}$ da solução extratora. Os frascos sofreram agitação por 1 hora e os extratos coletados por filtração. Colocando as resinas em seus respectivos frascos foi adicionado a cada frasco a respectiva solução extratora, até completar $100 \mathrm{~mL}$.

Em seguida, para cada extrato coletado por filtração foi submetido ao seguinte tratamento, (Equação 2):

$5 \mathrm{~mL}$ extrato $+10 \mathrm{~mL}$ solução 1,10-fenantrolina

Para verificar a labilidade dos elementos do solo em função da umidade, foram deixadas por 10 minutos em contato com o sol e logo submetidas a detecção por espectrofotometria UV-VIS. Utilizou-se a curva de calibração (Figura 1) para obter as concentrações devido os valores de absorvância, de acordo com as (Tabela 1 e Tabela 2)

Figura 1 - Curva de Calibração utilizada na determinação de Ferro em solos, após extração com resina.

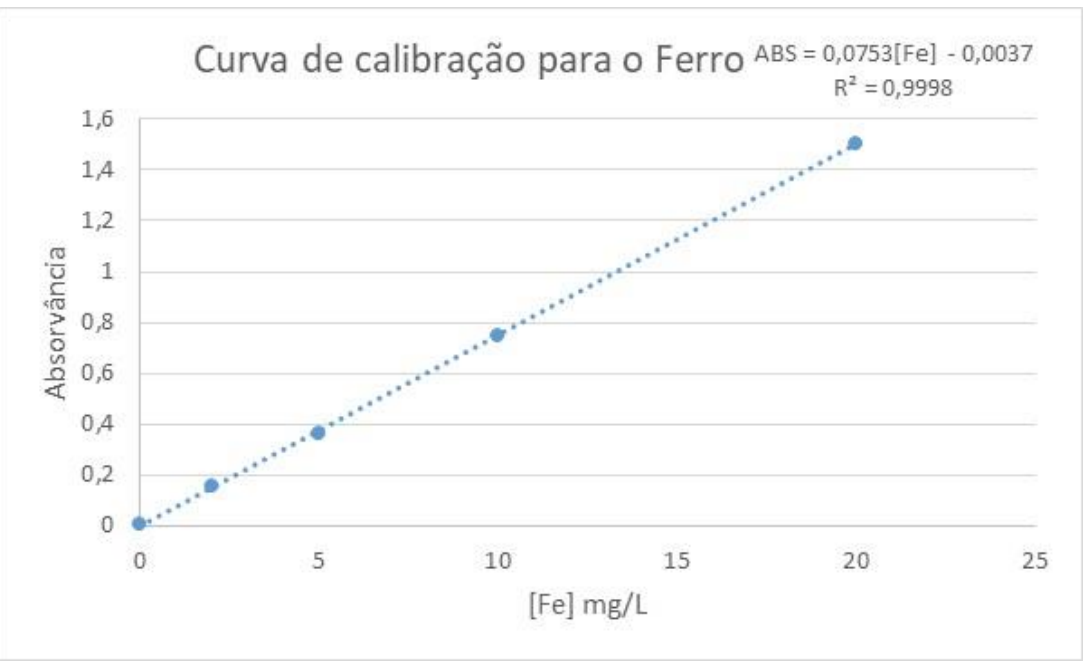




\section{RESULTADOS E DISCUSSÃO}

Os valores referentes a presença de ferro foram obtidos pela equação fornecida pela curva de calibração, e estes são exibidos nas Tabelas 1 e 2.

Tabela 1 - Valores de concentração de ferro encontrados nas amostras de solo da Fazenda Laboratório do Unifor-MG, contidos em vasos.

\begin{tabular}{|c|c|}
\hline Quantidade de solo (g) & Concentração (mg/L) \\
\hline 280 & 0,52 \\
\hline 320 & 0,57 \\
\hline 360 & 0,27 \\
\hline 400 & 0,29 \\
\hline
\end{tabular}

A Tabela 1 mostra que nos vasos com maior quantidade de água o ferro estava mais disponível. O que é compreensível devido ao aumento de solvente (no caso a água) para o elemento em questão, que solubiliza de forma mais eficaz.

Tabela 2 - Valores de concentração de ferro encontrados nas amostras de solo do Museu do Carste em Pains-MG, contidos em vasos.

\begin{tabular}{|c|c|}
\hline Quantidade de solo $(\mathrm{g})$ & Concentração $(\mathrm{mg} / \mathrm{L})$ \\
\hline 280 & 0,33 \\
\hline 320 & 0,39 \\
\hline 360 & 0,35 \\
\hline 400 & 0,32 \\
\hline
\end{tabular}

Nota-se que o solo da fazenda laboratório apresenta um maior teor de ferro, quando o nível de água é elevado. Isto porque, a água favorece a mobilidade do elemento e consequentemente a sua transferência para a resina. O mesmo não ocorreu para o solo do Museu do Carste, pois aquela região apresenta grande quantidade de cálcio no solo, o que impede que micronutrientes (como o ferro) alcancem grande mobilidade. Desta forma, entende-se que o teor de ferro no solo cárstico pode até ser alto, porém a disponibilidade do metal é pequena. E tal fato é corroborado ao se comparar com o solo da fazenda, onde há grande teor de ferro e a disponibilidade é maior. 


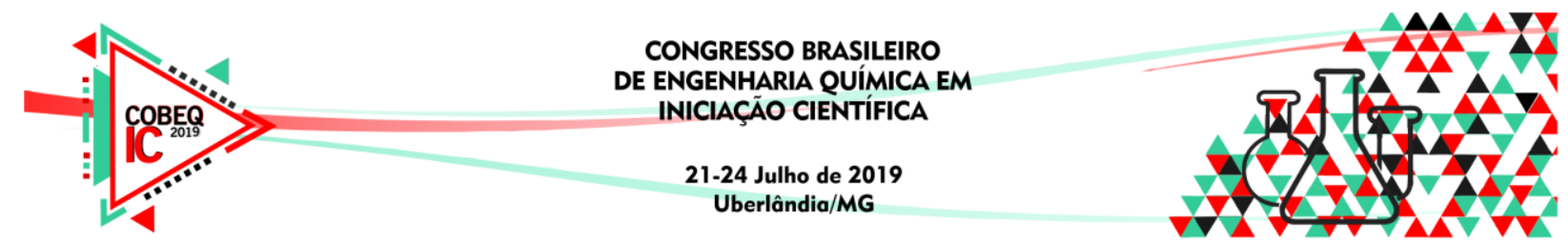

O estudo permitiu observar que se o solo não apresenta teor satisfatório de umidade, a extração com a resina trocadora de íons fica comprometida, e desta forma, tem-se a umidade como um fator crucial na determinação.

\section{CONCLUSÃO}

Com base nos dados obtidos, pode-se perceber que uma maior presença de água, e consequentemente maior umidade no solo da Fazenda Laboratório, favorece a detecção do elemento ferro. Tal fato permite a resina extrair mais facilmente o metal. Contudo, o solo do Museu da cidade de Pains, é um solo de origem Cárstica, ou seja, possui uma grande quantidade de Cálcio e Magnésio, e estes elementos interferem na determinação do ferro utilizando o método da resina de troca iônica.

\section{REFERÊNCIAS}

ALMEIDA, A. M. A resina de troca iônica como extrator multielementar em análise de solos para fins de fertilidade. Dissertação de mestrado, Unicamp, IQ, Campinas, 1999.

HELFFERICH, F.. Ion Exchange. Mc graw-hill book company, Inc., New York - USA. 1962.

SCHARLAU, A. V.. Avaliação da extração de íons nitrato e íons amônio utilizando resinas de trocas catiônicas e aniônicas. Trabalho de Conclusão de Curso - Graduação em Química Bacharelado - Universidade de Passo Fundo, Passo Fundo - RS, 2012.

TEODORO, M. S.. Extração multielementar para amostras de solos utilizando resina de troca iônica. Dissertação de mestrado, Instituto Agronômico de Campinas, Campinas SP, 2014.

VOGEL, A. Análise química quantitativa. 6. ed. Rio de Janeiro: Livros Técnicos e Científicos Editora S.A., 2002. 462 p. 